\title{
Comparison of nanometer-thick films by $x$-ray reflectivity and spectroscopic ellipsometry
}

\author{
Sandeep Kohli, ${ }^{\text {a) }}$ Christopher D. Rithner, and Peter K. Dorhout \\ Department of Chemistry, Colorado State University, Fort Collins, Colorado 80523 \\ Ann M. Dummer and Carmen S. Menoni \\ NSF ERC for Extreme Ultraviolet Science and Technology, Department of Electrical and Computer \\ Engineering, Colorado State University, Fort Collins, Colorado 80523
}

(Received 24 March 2004; accepted 15 November 2004; published online 10 January 2005)

\begin{abstract}
Films of tantalum pentoxide $\left(\mathrm{Ta}_{2} \mathrm{O}_{5}\right)$ with thickness of 10-100 nm were deposited on $\mathrm{Si}$ wafers and have been compared using spectroscopic ellipsometry (SE) and x-ray reflectivity (XRR). $\left(\mathrm{Ta}_{2} \mathrm{O}_{5}\right)$ was chosen for comparison work based on various criterions for material selection outlined in this article. Measurements were performed at six positions across the sample area to take into consideration thickness and composition inhomogeneity. SE and XRR fitted curves required the incorporation of a linearly graded interface layer. SE systematically measured higher values of film thickness as compared to XRR. A linear equation was established between the thickness measurements using SE and XRR. The slope of the linear equation established was found to be $1.02 \pm 0.01$. However, the intercepts were found to be $1.7 \pm 0.2$ and $2.6 \pm 0.3$ when the interface was excluded and included, respectively. These differences in the values of intercepts were attributed to the uncertainties in the determination of the interface layer. () 2005 American Institute of Physics. [DOI: $10.1063 / 1.1848660]$
\end{abstract}

\section{INTRODUCTION}

With the shrinking device structures employing nanometer thick films, it becomes necessary to accurately determine film thickness with low uncertainties. X-ray reflectivity (XRR), spectroscopic ellipsometry (SE), scanning electron microscopy (SEM), cross-sectional-transmission electron microscopy (X-TEM), and atomic force microscopy (AFM) are the techniques used for estimating the thickness of nanometer-dimensioned thin films deposited on bulk substrates. SEM and X-TEM require significant sample preparation and at times are destructive, which may not yield the true film thickness. Thickness measurements using AFM require the presence of a sharp step between the surface of the substrate and the film surface that is not always available. Another drawback to SEM, X-TEM, and AFM is that these techniques cannot be easily integrated to high-throughput thin film deposition equipment.

$\mathrm{SE}$ and XRR are nondestructive techniques used frequently for measuring the thickness of thin film structures with minimal sample preparation. While XRR is used for measuring thickness and density of thin films and interface layers, SE is essentially used for finding the optical constants (refractive index $n$ and extinction coefficient $k$ ) and thickness of thin films and their interfaces. Both the techniques utilize extensive modeling principles and require some available information related to the film structures. However, both the techniques work on different principles. XRR measurements are more sensitive to the electron density differences be-

\footnotetext{
${ }^{\text {a) }}$ Author to whom correspondence should be addressed; electronic mail: skohli@lamar.colostate.edu
}

tween the film and the substrate or interfacial layer. SE measurements are dependent on the contrast between the optical constants of the film and the underlying substrate or interfacial layer. More details relevant to the principles and techniques for ellipsometry ${ }^{1-3}$ and $\mathrm{x}$-ray reflectivity are available in the literature. ${ }^{4,5}$

There have been several attempts to calibrate the differences between thickness measurements by SE and XRR. Using self assembled monolayers of alkylsiloxanes on silicon substrates; Wasserman et al. ${ }^{6}$ found that thickness measurements using SE were systematically higher than those reported by XRR. However, in their attempts to calibrate SE with XRR using spin coated poly(tert-butyl acrylate) PtBA films on silicon substrates, Richter et al. ${ }^{7}$ reported similar values of film thickness measured using SE as compared to XRR measurements. Thickness measurements of 5-35 thin dip-coated perfluoropolyether (PFPE) polymer films on silicon substrate and silicon substrates with $120 \AA a$-C: $\mathrm{H}$ coating were carried out by Toney et al. using XRR and SE. ${ }^{8}$ A linear least-squares fit with a slope of around 1.0 was found for PFPE films irrespective of the substrate. However, the value of the intercept for the least-squares fit line was found to be $5.3 \pm 0.9 \AA$ and $2.7 \pm 1 \AA$ for films deposited on silicon substrates and $a-\mathrm{C}: \mathrm{H}$, respectively. They had attributed the nonzero intercepts to the adsorption of hydrocarbon contaminants on the native silicon oxide layer of the silicon substrates for the $a-\mathrm{C}: \mathrm{H}$ surfaces. ${ }^{8}$ In a recent attempt at metrological characterization of nanometer film thickness standards for XRR and SE applications using 6-1000 nm $\mathrm{SiO}_{2}$ layer on $\mathrm{Si}$ substrate, Hasche et al. ${ }^{9}$ had reported higher values of thickness measured using SE than XRR. They had 
also found that the XRR measurements were consistent with the thickness estimation by scanning force microscopy.

The following equations best summarize the relationship between SE and XRR in the papers described above

$$
d_{\mathrm{SE}}(\AA)=\left[0.999 \times d_{\mathrm{XRR}}(\AA)-0.719 \AA\right]
$$

(Ref. 7),

$$
d_{\mathrm{SE}}(\AA)=\left[(0.99 \pm 0.05) \times d_{\mathrm{XRR}}(\AA)+(5.3 \pm 0.9) \AA\right]
$$

(Ref. 8),

$$
d_{\mathrm{SE}}(\AA)=\left[(1.0 \pm 0.08) \times d_{\mathrm{XRR}}(\AA)+(2.7 \pm 1.0) \AA\right]
$$

(Ref. 8),

$$
d_{\mathrm{SE}}(\mathrm{nm})=\left[1.012 \times d_{\mathrm{XRR}}(\mathrm{nm})+1.285 \mathrm{~nm}\right]
$$

(Ref. 9).

Equations (2a) and (2b) describe a PFPE film on a $\mathrm{Si}$ substrate and an $a-\mathrm{C}: \mathrm{H} / \mathrm{Si}$ substrates respectively. As seen in Eqs. (1)-(3) while the slope in all the equations were found to be around 1.0, the values of intercept varied over a large range. Thickness, composition inhomogeneity, and poorly characterized interfaces could be some of the reasons for this variation. In fact only Eq. (3) had been based on some comprehensive studies performed by authors on $\mathrm{SiO}_{2}$ layers deposited on Si substrate. ${ }^{9}$ As we discuss below, $\mathrm{SiO}_{2} / \mathrm{Si}$ is clearly not a system of choice for this comparison work in the laboratory.

Before attempting to compare the thickness measurements using XRR and SE, the following considerations should be noted.

1. SE and XRR are both based on the reflection of incident radiation from the interfaces between the film and the underlying substrate or layer (as well as film and air interface). The films should be smooth and deposited on a nearly atomically flat surface, so that the interface and surface roughness do not destroy the interface information.

2. The thickness of the film should be small enough such that the incident radiation used in XRR and SE penetrates to the bottom of the film.

3. Incident radiation should not chemically, optically, or structurally destabilize the specimen under investigation.

4. The nonuniformity of the film thickness, density, and optical constants should be included in the analysis.

5. The presence of interfaces should also be taken into consideration for comparison.

6. A large contrast must exist between the optical constants and electron densities of the layer and substrate.

In the present study, we report a comparison of XRR and SE measurements on 10-100 nm sputter-deposited $\mathrm{Ta}_{2} \mathrm{O}_{5}$ films on a smooth Si (100) substrate with native oxide layer. The choice of material in our studies is unique since we have not used polymer, metal, or $\mathrm{SiO}_{2}$ films on $\mathrm{Si}$ substrate. While sufficient contrast exists between the optical constants of $\mathrm{Si}$ and $\mathrm{SiO}_{2}$, the electron densities (which are related to material density) ${ }^{5}$ of $\mathrm{Si}$ and $\mathrm{SiO}_{2}$ are quite similar. Hasche et al. had used a photon energy of $1841 \mathrm{eV}$ for XRR measurements,
TABLE I. Deposition conditions for $\mathrm{Ta}_{2} \mathrm{O}_{5}$ films

\begin{tabular}{ll}
\hline \hline & Ta metal \\
Target material & $99.999 \%$ \\
\hline Deposition rate & $3.2 \AA / \mathrm{s}$ \\
Deposition source ion energy & $1250 \mathrm{eV}$ \\
Beam voltage & $1250 \mathrm{~V}$ \\
Beam current (ion flux) & $600 \mathrm{~mA}$ \\
Accelerating voltage & $250 \mathrm{~V}$ \\
Assist source condition & Beam off \\
Chamber temperature & $\sim 115^{\circ} \mathrm{C}$ \\
Base pressure & $1.0^{-6} \mathrm{Torr}$ \\
Oxygen flow rate & $37 \mathrm{sccm}$ \\
Argon flow rate & $31 \mathrm{sccm}$ \\
\hline \hline
\end{tabular}

which is just above the Si K-edge absorption. ${ }^{9}$ At these energies the authors found sufficient contrast between the electron densities of both materials and the results were reported with low uncertainties. Clearly the $\mathrm{SiO}_{2} / \mathrm{Si}$ system is not a material of choice for metrological characterization of nanometer film thickness standards using frequently employed laboratory x-ray sources that can be used with high throughput thin film deposition processes. In contrast, the optical constants and electron density of $\mathrm{Ta}_{2} \mathrm{O}_{5}$ are considerably different from the underlying substrate and air. Unlike polymer films, the $\mathrm{Ta}_{2} \mathrm{O}_{5}$ is mechanically and chemically stable toward the incident radiation used in the study over a long period of time under the ambient conditions. Choice of metal films was excluded since the high-density metal films are transparent for SE studies over a limited range of thickness lower than those used in our studies. $\mathrm{Ta}_{2} \mathrm{O}_{5}$ is also transparent to the radiation used in the present study for XRR and SE for the thickness ranges being investigated. $\mathrm{Ta}_{2} \mathrm{O}_{5}$ is also an important material for technological application in telecommunication filters.

\section{EXPERIMENT}

Films of controlled thickness ranging from 10-100 nm $\mathrm{Ta}_{2} \mathrm{O}_{5}$ were deposited on $\mathrm{Si}$ (100) substrates using a dual ion beam sputtering deposition tool (Spector IBD system, Veeco Inc., Fort Collins, CO). Oxide films produced in this system are typically dense and amorphous. ${ }^{10,11}$ The IBD system is capable of producing films thinner than $10 \mathrm{~nm}$ that may be uniformly deposited over an area of 6 in. diameter. The experimental conditions for depositing $\mathrm{Ta}_{2} \mathrm{O}_{5}$ films are listed in Table I. The 1 in. $\times 2$ in. Si substrates were cleaned with alcohol and dried before being placed in the vacuum chamber. No attempts were made to remove the native oxide layer.

XRR and glancing angle x-ray diffraction (GAXRD) were performed using a Bruker D-8 Discover instrument. Variable angle spectroscopic ellipsometer (VASE) by J. A. Woollam Co. (Lincoln, NE) was used for SE measurements. SE measurements were performed at an angle of incidence of $75^{\circ}$ and spectroscopic results were simulated using WVASE $^{\mathrm{TM}}$ software provided by the manufacturer. ${ }^{12}$ More details outlining the conditions for XRR, GAXRD, ${ }^{13,14}$ and ellipsometry ${ }^{15}$ measurements and simulations are published elsewhere. XRR and SE measurements were performed and 


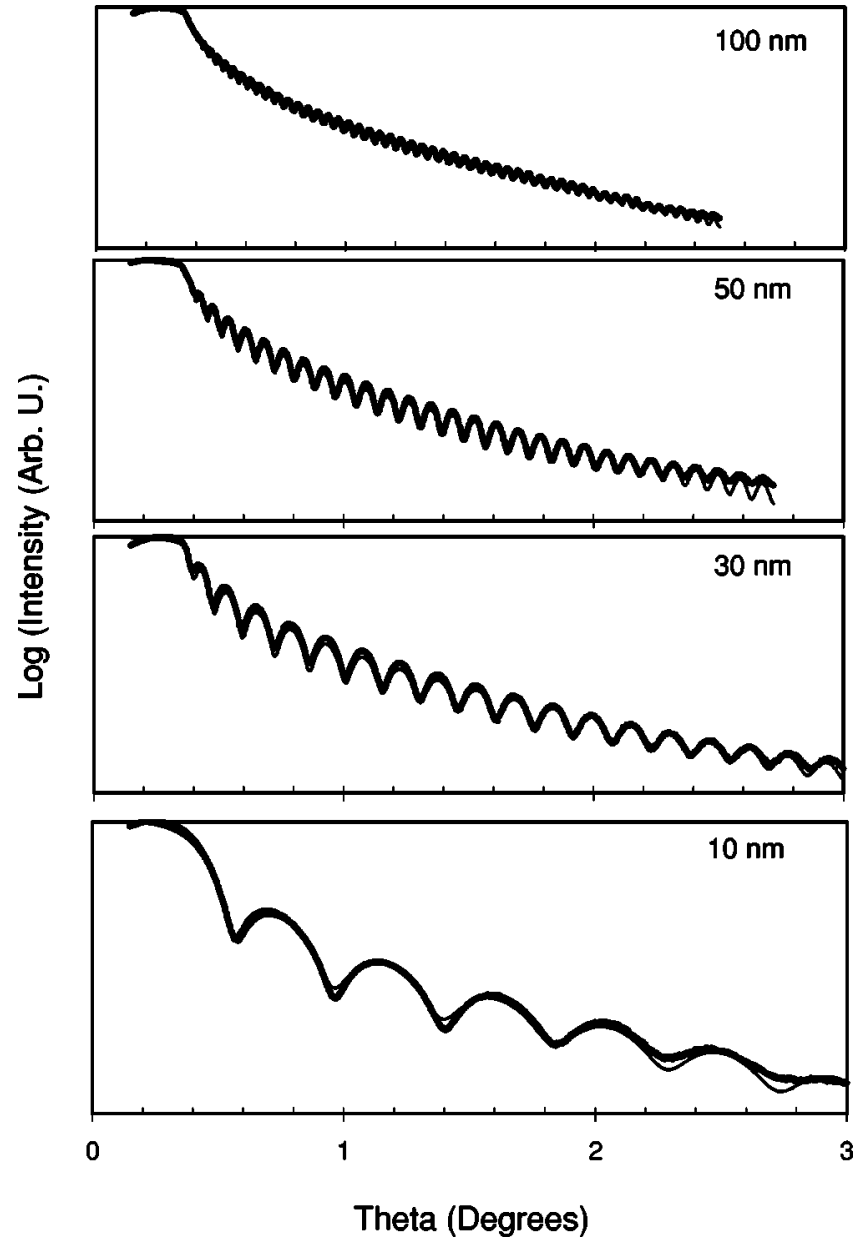

FIG. 1. Experimental $(\bullet)$ and simulated (-) x-ray reflectivity curves for $10-100 \mathrm{~nm} \mathrm{Ta}{ }_{2} \mathrm{O}_{5}$ films.

simulated at six positions across the length and breadth of the film surface.

\section{RESULTS AND DISCUSSION}

The absence of any crystalline features for the asdeposited film in the GAXRD patterns indicated the amorphous nature of the films. Figure 1 shows the representative experimental and simulated XRR curves for the films. The film structures were fitted using a single $\mathrm{Ta}_{2} \mathrm{O}_{5}$ layer and a thin interface layer comprising of $\mathrm{Ta}-\mathrm{Si}-\mathrm{O}$, between the $\mathrm{Ta}_{2} \mathrm{O}_{5}$ layer and the $\mathrm{Si}$ substrate. This interface was likely to be formed as a result of the intermixing of $\mathrm{Ta}_{2} \mathrm{O}_{5}, \mathrm{SiO}_{2}$ (native oxide), and $\mathrm{Si}$. Hence, a linear grading was assumed in the density of this interface layer, with higher density $\mathrm{Ta}_{2} \mathrm{O}_{5}$ top and lower density silicon bottom. The density of the $\mathrm{Ta}_{2} \mathrm{O}_{5}$ top layer in the interface was fixed at the estimated density of the $\mathrm{Ta}_{2} \mathrm{O}_{5}$ film, while the density of the interface bottom was fixed to be the density of silicon metal. The thickness, density, and roughness of the film structure were varied to get the best-fit results. The data from the simulated results are presented in Table II. The modeled XRR results show the presence of $10-100 \mathrm{~nm}$ as-deposited $\mathrm{Ta}_{2} \mathrm{O}_{5}$ films with density in the range $7.9-8.2 \mathrm{gm} / \mathrm{cm}^{3}$. These values are comparable to the density of crystalline $\mathrm{Ta}_{2} \mathrm{O}_{5}\left(8.2 \mathrm{gm} / \mathrm{cm}^{3}\right)$ reported in the literature. The graded interface layer was found to vary between 0.9 and $2.4 \mathrm{~nm}$. Large uncertainties were observed in the estimated values of thickness and density of this interface layer. This indicates significant nonuniformity of the layer formed at the $\mathrm{Ta}_{2} \mathrm{O}_{5} / \mathrm{Si}$ interface.

The experimental and simulated results for SE are shown in Fig. 2. Cauchy's dispersion model layer was used for the estimation of thickness and optical constants of the $\mathrm{Ta}_{2} \mathrm{O}_{5}$ layer. ${ }^{12}$ A model layer to simulate the surface roughness (50\% voids and 50\% underlying layer) was included at the air-film interface. The film structures were simulated with mean squared error (MSE) values lower than 4 with the introduction of a thin graded interface layer described in the previous paragraph. The optical constants of the $\mathrm{Ta}_{2} \mathrm{O}_{5}$ component were coupled to the optical constants of the Cauchy's $\mathrm{Ta}_{2} \mathrm{O}_{5}$ layer. The simulated results along with MSE values are shown in Table III.

Figure 3 shows the variation of refractive index as a function of wavelength for the deposited $\mathrm{Ta}_{2} \mathrm{O}_{5}$ films. The solid line represents the average values of the refractive index for the six measurements performed while symbols represent the individual results. Refractive index values for the $10 \mathrm{~nm}$ film showed larger deviations from their average values across the wavelengths investigated. This was not the case with other films. As seen in the XRR and SE fitted results, the $10 \mathrm{~nm}$ film had larger nonuniformity in thickness as compared to the other films. The $10 \mathrm{~nm}$ film was deposited over a relatively short period of time; hence, the film deposition during that period was likely to exhibit greater inhomogeneity in composition and thickness, as compared to other films. Thus, large variations in refractive index across the film surface could possibly be associated with compositional inhomogeneity within the $10 \mathrm{~nm} \mathrm{Ta}_{2} \mathrm{O}_{5}$ film.

The refractive index of $30-100 \mathrm{~nm}$ films at $\lambda=550 \mathrm{~nm}$ was found to lie in the range 2.13-2.15. These results are consistent with the results reported in literature. ${ }^{16,17}$ In the past, the refractive index of tantalum oxide films had been shown to be dependent on the O/Ta ratio. ${ }^{16,18}$ Tantalum sub-

TABLE II. Average thickness and density values obtained from XRR for $\mathrm{Ta}_{2} \mathrm{O}_{5}$ layered structures, with "linearly graded interface" layer. The values are reported with (esd), the standard deviations from the average values for-six measurements performed over each sample.

\begin{tabular}{|c|c|c|c|c|c|c|c|c|}
\hline \multirow[t]{2}{*}{$\begin{array}{l}\text { Aimed thickness } \\
(\mathrm{nm})\end{array}$} & \multicolumn{2}{|c|}{100} & \multicolumn{2}{|c|}{50} & \multicolumn{2}{|c|}{30} & \multicolumn{2}{|c|}{10} \\
\hline & $\begin{array}{l}\text { Thickness } \\
\text { (nm) }\end{array}$ & $\begin{array}{l}\text { Density } \\
\left(\mathrm{gm} / \mathrm{cm}^{3}\right)\end{array}$ & $\begin{array}{c}\text { Thickness } \\
\text { (nm) }\end{array}$ & $\begin{array}{l}\text { Density } \\
\left(\mathrm{gm} / \mathrm{cm}^{3}\right)\end{array}$ & $\begin{array}{l}\text { Thickness } \\
\text { (nm) }\end{array}$ & $\begin{array}{l}\text { Density } \\
\left(\mathrm{gm} / \mathrm{cm}^{3}\right)\end{array}$ & $\begin{array}{c}\text { Thickness } \\
\text { (nm) }\end{array}$ & $\begin{array}{l}\text { Density } \\
\left(\mathrm{gm} / \mathrm{cm}^{3}\right)\end{array}$ \\
\hline $\mathrm{Ta}_{2} \mathrm{O}_{5}$ layer & $99.0(0.4)$ & $8.4(0.2)$ & $48.4(0.1)$ & $8.2(0.2)$ & $27.2(0.3)$ & $8.1(0.1)$ & $9.3(0.1)$ & $7.6(0.1)$ \\
\hline Graded interface layer & $2.0(0.4)$ & & $2.0(0.3)$ & & $1.6(0.2)$ & & $0.9(0.1)$ & \\
\hline $\mathrm{Ta}_{2} \mathrm{O}_{5}$ layer+interface & $101(0.5)$ & - & $50.3(0.3)$ & - & $28.8(0.3)$ & - & $10.2(0.1)$ & - \\
\hline
\end{tabular}




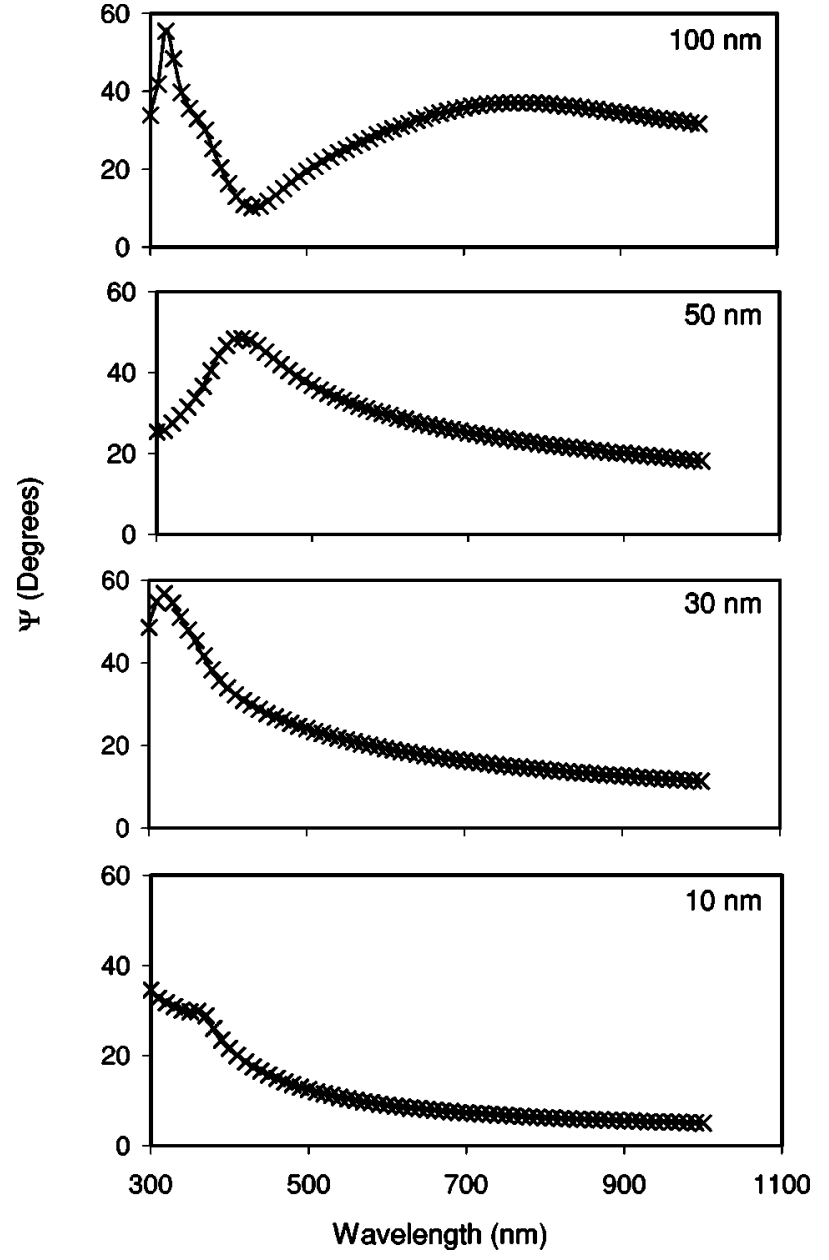

FIG. 2. Variation of the spectroscopic ellipsometry parameter " $\psi$ " on the incident wavelength for $\mathrm{Ta}_{2} \mathrm{O}_{5}$ films, measured at an angle on incidence of $75^{\circ}$. Experimental points are represented by $(\mathrm{X})$ while solid lines show the simulated results.

oxide films ${ }^{16}$ had been shown to exhibit higher refractive indices as compared to stoiochiometric films, while oxygen rich films ${ }^{18}$ exhibited lower refractive indices. However, Cevro and Carter $^{19}$ had observed that the refractive index of sputter-deposited $\mathrm{Ta}_{2} \mathrm{O}_{5}$ varied from 2.16-2.11 as the oxygen fraction in the chamber was varied from $32 \%$ to $80 \%$, as measured using transmission curves. The presence of pores or defect voids in the films is also likely to reduce the effective refractive index of $\mathrm{Ta}_{2} \mathrm{O}_{5}$ films. ${ }^{20}$ Since the films were deposited under the same conditions, it is likely that the

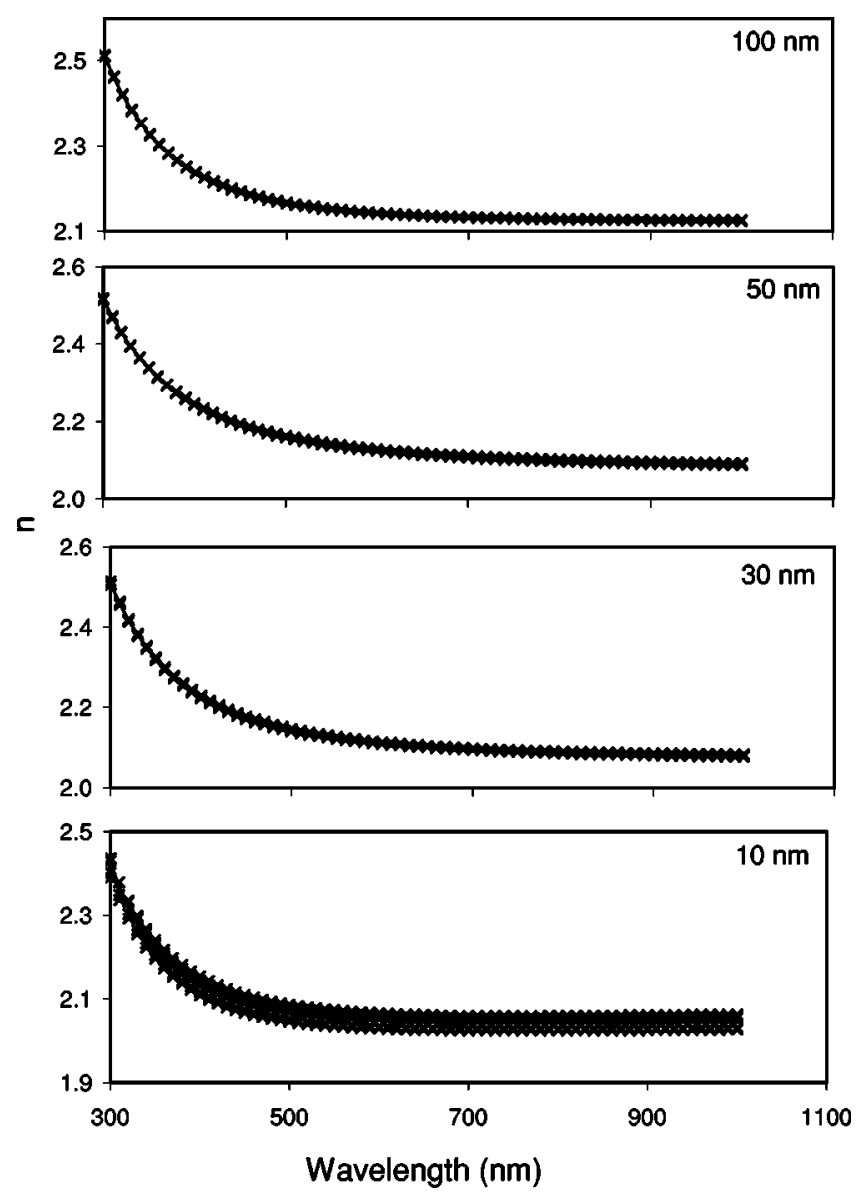

FIG. 3. The wavelength dependence of the refractive index for $10-100 \mathrm{~nm}$ $\mathrm{Ta}_{2} \mathrm{O}_{5}$ films. The solid lines represent the average value of the refractive index while the symbols represent the individual data points.

lower refractive index of the $10 \mathrm{~nm} \mathrm{Ta}_{2} \mathrm{O}_{5}$ was due to an increased number of voids or pores in the film.

The ellipsometry results systematically indicated higher film thickness as compared to XRR measurements. These results are consistent with the results reported earlier in the literature. ${ }^{6,9}$ A comparison of the thickness values observed for well-characterized $\mathrm{Ta}_{2} \mathrm{O}_{5}$ films using SE and XRR are shown in Fig. 4. As seen in the figure, while the values of the slope of the established linear equation were observed to be the same when the interface layer was included [Fig. 4(a)] or excluded [Fig. 4(b)], differences were observed in the values of intercept under the two scenarios. These differences in the

TABLE III. Average thickness obtained from SE for $\mathrm{Ta}_{2} \mathrm{O}_{5}$ layered structures. The values are reported with (esd), the standard deviations from the average values for six measurements performed over each sample. The refractive index values at $\lambda=550 \mathrm{~nm}$ are also shown.

\begin{tabular}{|c|c|c|c|c|}
\hline Aimed thickness (nm) & 100 & 50 & 30 & 10 \\
\hline surface roughness $(\mathrm{nm})$ & $2.7(0.1)$ & 0 & 0 & $1.2(0.6)$ \\
\hline Cauchy layer (nm) & $100.7(0.5)$ & $50.7(0.3)$ & $29.2(0.2)$ & $10.5(0.5)$ \\
\hline Graded interface layer (nm) & $2.7(0.1)$ & $1.9(0.1)$ & $2.3(0.1)$ & $2.3(0.1)$ \\
\hline $\mathrm{Ta}_{2} \mathrm{O}_{5}$ layer $(\mathrm{nm})$ & $103.4(0.4)$ & $50.7(0.3)$ & $29.2(0.2)$ & $11.7(0.2)$ \\
\hline $\mathrm{Ta}_{2} \mathrm{O}_{5}$ layer+interface $(\mathrm{nm})$ & $106.1(0.4)$ & $52.6(0.3)$ & $31.5(0.3)$ & $14.0(0.1)$ \\
\hline Refractive index $(n)(\lambda=550 \mathrm{~nm})$ & $2.152(0.001)$ & $2.141(0.002)$ & $2.125(0.002)$ & $2.049(0.023)$ \\
\hline MSE & $3.9(0.3)$ & $3.1(0.6)$ & $2.5(0.5)$ & $3.2(0.7)$ \\
\hline
\end{tabular}




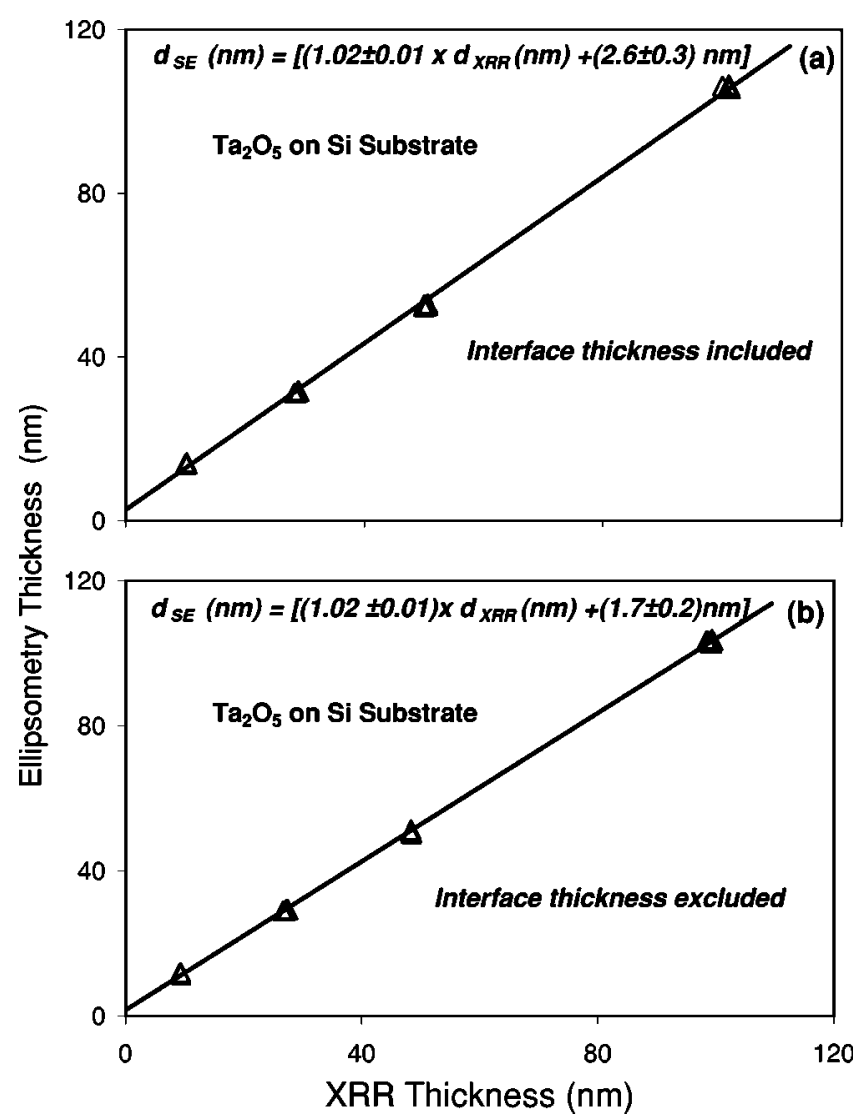

FIG. 4. Comparisons of film thickness using spectroscopic ellipsometry and $\mathrm{x}$-ray reflectivity. Symbols represent the individual results and solid line shows the fitted results by a linear least-squares analysis. The linear equations fitting the data points are also shown for the interface layer (a) included and (b) excluded.

values of intercepts were possibly due to the uncertainties in the determination of the interface layer. An extrapolation of the set of data points in the current study clearly indicates that these differences are likely to be a substantial portion of film thickness for films thickness $<10 \mathrm{~nm}$. The reasons for nonzero intercepts in the linear relation between XRR and SE data observed in the present studies, and reported in earlier studies are not clear at the moment. More investigative studies involving different materials, satisfying the criteria outlined in this article and XRR studies at different $\mathrm{x}$-ray energies are needed.

\section{ACKNOWLEDGMENTS}

The authors would like to acknowledge the financial support provided by the NSF instrument Grant Nos. NSFCHE- 9808024 and NSF-DMR-0076180. This work was also supported in part by the NSF Engineering Research Centers Program under Grant No. EEC-0310717. C.S.M. acknowledges Veeco Instruments for the donation of the Spector IBD tool.

${ }^{1}$ J. A. Woollam, B. Johs, C. M. Herzinger, J. Hilfiker, R. Synowicki, and C. L. Bungay, Crit. Rev. Opt. Sci. Tech. 72, 3 (1999).

${ }^{2}$ J. A. Woollam, in Wiley Encylopedia of Electrical and Electronics Engineering, Supplement 1, edited by J. G. Webster (Wiley, New York, 2000), p. E109.

${ }^{3}$ K. Vedam, Thin Solid Films 313, 1 (1998).

${ }^{4}$ H. Kiessig, Ann. Phys. (Leipzig) 10(5) 769 (1931).

${ }^{5}$ V. P. Holy and T. U. Baumbach, High-Resolution X-ray Scattering from Thin Films and Multilayers, Vol. 149 (Springer, Berlin, 1999).

${ }^{6}$ S. R. Wasserman, G. M. Whitesides, I. M. Tidswell, B. M. Ocko, P. S. Pershan, and J. D. Axe, J. Am. Chem. Soc. III, 5852 (1989).

A. Richter, R. Guico, and J. Wang, Rev. Sci. Instrum. 72, 3004 (2001).

${ }^{8}$ M. F. Toney, C. M. Mate, K. A. Leach, and D. Pocker, J. Colloid Interface Sci. 225, 219 (2000).

${ }^{9}$ K. Hasche, P. Thomsen-Schmidt, M. Krumrey, G. Ade, G. Ulm, J. Stuempel, S. Schaedlich, W. Frank, M. Procop, and U. Beck, Proc. SPIE 5190, 165 (2003).

${ }^{10}$ C. Montcalm, S. M. Lee, D. Burtner, A. Dummer, D. Siegfried, I. Wagner, and M. Watanabe, Annual Technical Conference Proceedings - Society of Vacuum Coaters, Vol. 45, p. 245, 2002.

${ }^{11}$ R. Blacker, D. Deakins, I. Kameyama, A. Dummer, B. Buchholtz, D. Siegfried, and C. Montcalm, Annual Technical Conference Proceedings Society of Vacuum Coaters, Vol. 45, p. 232, 2002.

${ }^{12}$ Guide to using WVASE32 ${ }^{\text {TM }}$, J. A. Woolam Co., Inc., Lincoln, NE.

${ }^{13}$ S. Kohli, C. D. Rithner, and P. K. Dorhout, J. Appl. Phys. 91, 1149 (2002).

${ }^{14}$ S. Kohli, J. A. Theil, R. D. Snyder, C. D. Rithner, and P. K. Dorhout, J. Vac. Sci. Technol. B 21, 719 (2003).

${ }^{15}$ S. Kohli, D. Niles, C. D. Rithner, and P. K. Dorhout, Adv. X-Ray Anal. 45, 352 (2002).

${ }^{16}$ H. Demiryont, J. R. Sites, and K. Geib, Appl. Opt. 24, 490 (1985).

${ }^{17}$ E. Franke, C. L. Trimble, M. J. DeVries, J. A. Woollam, M. Schubert, and F. Frost, J. Appl. Phys. 88, 5166 (2000).

${ }^{18}$ S. O. Kim, J. S. Byun, and H. J. Kim, Thin Solid Films 206, 102 (1991).

${ }^{19}$ M. Cevro and G. Carter, Opt. Eng. 34, 596 (1995).

${ }^{20}$ W. D. Westwood, R. J. Boynton, and S. J. Ingrey, J. Vac. Sci. Technol. 11, 381 (1974). 